\title{
Synthesis of porous reduced graphene oxide as metal-free carbon for adsorption and catalytic oxidation of organics in water
}

\author{
Wenchao Peng ${ }^{\mathrm{a}}$, Shizhen Liu ${ }^{\mathrm{a}}$, Hongqi Sun ${ }^{\mathrm{a}}$, Yunjin Yao ${ }^{\mathrm{a}, \mathrm{b}}$, Linjie Zhic, Shaobin Wang ${ }^{\mathrm{a}, *}$ \\ ${ }^{a}$ Department of Chemical Engineering, Curtin University, GPO Box U1987, Perth WA 6845, Australia \\ ${ }^{\mathrm{b}}$ School of Chemical Engineering, Hefei University of Technology, Hefei 230009, P.R. China \\ ${ }^{c}$ National Centre for Nanoscience and Technology, Chinese Academy of Sciences, Beijing, 100190, \\ P.R. China
}

\begin{abstract}
Activation of reduced graphene oxide (RGO) using $\mathrm{CO}_{2}$ to obtain highly porous and metal-free carbonaceous materials for adsorption and catalysis was investigated. The facile one-pot thermal process can simultaneously reduce graphene oxide and produce activated RGO without introducing any solid or aqueous activation agent. This process can significantly increase the specific surface area (SSA) of RGO from 200 to higher than $1200 \mathrm{~m}^{2} / \mathrm{g}$, and the obtained materials were proven to be highly effective for adsorptive removal of both anionic (phenol) and cationic (methylene blue, MB) organics from water. Moreover, the activated RGO materials exhibited much better activity in effective activation of peroxymonosulfate (PMS) to produce sulfate radicals for oxidative degradation of MB.
\end{abstract}

Key words: Reduced graphene oxide, $\mathrm{CO}_{2}$ Activation, Porous structure, Adsorption, Catalytic oxidation

\footnotetext{
* Corresponding author. Tel: +61 8 92663776, Fax: +61 8 92662681. E-mail address: shaobin.wang@curtin.edu.au (S. Wang)
} 


\section{Introduction}

Carbon materials, including activated carbon, carbon nanotube (CNT), and carbon black are all effective sorbents for pollutant removal from water or air due to their large specific surface area $(\mathrm{SSA})^{1-3}$. Graphene, a new carbon material with single or multiple carbon layers and $\mathrm{sp}^{2}$-hybridized carbon lattice, possesses many unique features such as good electrical, thermal, and mechanical properties $^{4}$. It is also a good sorbent candidate ${ }^{5}$ with theoretical SSA of $2630 \mathrm{~m}^{2} / \mathrm{g}$, but the reported SSA values of reduced graphene oxide (RGO) derived from chemically synthesized graphene oxide (GO) were only less than $100 \mathrm{~m}^{2} / \mathrm{g}^{6}$. To improve RGO's SSA as well as other characteristics, for examples, adsorption capacity, conductivity, and supercapacity, researchers have used potassium hydroxide to activate $\mathrm{RGO}^{7,8}$. This method is effective, but the process is complicated and will introduce foreign chemicals which are difficult to remove. Carbon dioxide activation of carbon materials is another effective method, however, no investigation has been reported on RGO activation using $\mathrm{CO}_{2}$.

Organic pollutants in water have been a big issue in water contamination. Removal of these organics can be achieved by several technologies. Among them, adsorption and catalytic oxidation processes are the most effective methods ${ }^{9}$. Catalytic oxidation can degrade organics to harmless compounds, $\mathrm{CO}_{2}$, $\mathrm{H}_{2} \mathrm{O}$ and inorganic ions, by the generated radicals, providing a better alternative than adsorption. Currently, most catalytic oxidation processes for radical generation employ metal-based materials as catalysts, which are expensive and could induce secondary pollution due to metal leaching and toxicity. Thus, using metal-free materials for organic oxidation in water is highly required for environmental benign processes ${ }^{10}$.

In this study, a facile one-pot thermal process was developed to prepare activated RGO. Chemically synthesized GO was used as a starting material, and carbon dioxide was selected as an activation agent. The activated RGO (A-RGO) materials were demonstrated to be highly efficient for adsorptive 
removal of phenol and methylene blue (MB) from aqueous solution. Moreover, the A-RGO materials were also tested for the catalytic oxidation of MB using peroxymonosulfate (PMS) as an oxidant. Based on both the adsorption and catalytic oxidation results, activated RGO materials demonstrated to be effective metal free carbons for green processes.

\section{Experimental}

\subsection{Materials and chemicals}

Graphite powder (purity 99.9995\%), sulphuric acid (95-97\%), sodium nitrate, and MB were obtained from Sigma-Aldrich. Potassium peroxymonosulfate $\left(2 \mathrm{KHSO}_{5} \cdot 3 \mathrm{KHSO}_{4} \cdot \mathrm{K}_{2} \mathrm{SO}_{4}\right.$ available as Oxone, PMS) was also obtained from Sigma-Aldrich. Hydrogen peroxide (30\%) was purchased from Chem-Supply. Potassium permanganate, phenol and ammonia solution (28\%) were obtained from Ajax Finechem. Hydrochloric acid (32\%, analytical grade) was obtained from Biolab.

\subsection{Synthesis of GO}

The Hummer's method was used to synthesize GO from graphite powder ${ }^{11}$. Briefly, graphite $(2 \mathrm{~g})$ was mixed with $\mathrm{NaNO}_{3}(1 \mathrm{~g})$ and $\mathrm{H}_{2} \mathrm{SO}_{4}(50 \mathrm{~mL})$ at $0{ }^{\circ} \mathrm{C}$, then $\mathrm{KMnO}_{4}(6 \mathrm{~g})$ was slowly added into the system. Then, the mixture was stirred at room temperature for $30 \mathrm{~min}$ after being kept at $0{ }^{\circ} \mathrm{C}$ for $2 \mathrm{~h}$. Distilled water $(100 \mathrm{~mL})$ was slowly added into the system, the temperature was kept well below $98{ }^{\circ} \mathrm{C}$ for $3 \mathrm{~h}$. The mixture was further treated with $5 \% \mathrm{H}_{2} \mathrm{O}_{2}(50 \mathrm{~mL})$, filtered and washed with distilled water. The obtained GO was dried at room temperature under vacuum condition.

\subsection{Thermal reduction of GO and activation of RGO}

The dried GO was first added into a quartz boat and put into a tubular furnace. $\mathrm{A} \mathrm{N}_{2}$ flow (50 $\mathrm{mL} / \mathrm{min}$ ) was then introduced to remove air for $2 \mathrm{~h}$. The temperature started to increase to $250{ }^{\circ} \mathrm{C}$ within $90 \mathrm{~min}$ and was maintained at that temperature for $30 \mathrm{~min}$ to transform GO to RGO. The temperature was then increased to $800{ }^{\circ} \mathrm{C}$ at a rate of $5{ }^{\circ} \mathrm{C} / \mathrm{min}$. After that, $\mathrm{N}_{2}$ was switched to $\mathrm{CO}_{2}$ at the same gas flow rate to perform activation process. Different activation times $(25,60$, and 75 min) 
were used to obtain A-RGO-25, A-RGO-60, and A-RGO-75 samples. After the activation process, $\mathrm{CO}_{2}$ flow was changed to $\mathrm{N}_{2}$ and the temperature dropped down naturally to room temperature.

\subsection{Characterization of carbon materials}

Surface area and pore size measurements of GO, RGO and A-RGO samples were carried out by $\mathrm{N}_{2}$ adsorption analysis at $-196{ }^{\circ} \mathrm{C}$ using a Gemini 2360 . All samples were degassed at $100{ }^{\circ} \mathrm{C}$ for $4 \mathrm{~h}$ prior to the adsorption experiments. SSA was derived from the Brunauer-Emmett-Teller (BET) equation and pore volume was obtained using the adsorption value at $p / p^{0}=0.95$. The pore size distribution was obtained by the Barrett-Joyner-Halenda (BJH) method. FT-IR spectra of these materials were recorded on a Perkin-Elmer Spectrum 100 with a resolution of $4 \mathrm{~cm}^{-1}$ in transmission mode at room temperature. TGA was performed by heating the samples in an air flow at a rate of $100 \mathrm{~mL} / \mathrm{min}$ using a Perkin-Elmer Diamond TG/DTA thermal analyzer with a heating rate of $10{ }^{\circ} \mathrm{C} / \mathrm{min}$. The samples for Raman analysis were prepared by pressing the powder using the hydraulic presser and carefully placed on the slide until analyzed. The spectra were acquired on a Bruker instrument.

\subsection{Batch adsorption experiments of phenol}

Batch adsorption experiments were performed on a model TU-454 Bench Top Shaking Incubator (Thermoline Scientific, Australia) with a shaking speed of $150 \mathrm{rpm}$. Typically, bottles containing about $10 \mathrm{mg}$ RGO or A-RGO were first filled with $50 \mathrm{~mL}$ phenol solutions with desired concentrations. Then they were sonicated for $2 \mathrm{~h}$ and placed in the shaker $\left(25^{\circ} \mathrm{C}\right)$ for $24 \mathrm{~h}$. The concentrations of phenol were analyzed using a HPLC with a UV detector at the wavelength of $270 \mathrm{~nm}$. The column used was C-18 and the mobile phase was a solution of $30 \% \mathrm{CH}_{3} \mathrm{CN}$ and $70 \%$ water.

\subsection{Adsorption and catalytic degradation of MB}

The adsorption of MB was performed in $250 \mathrm{~mL}$ beakers with magnetic stirring. Typically, $12 \mathrm{mg}$ prepared materials were dispersed in $200 \mathrm{~mL}, 10 \mathrm{ppm} \mathrm{MB}$ solution. The solutions were then kept 
stirring at $150 \mathrm{rpm}$ and water samples were taken out at varying time intervals. The solution samples were separated by a centrifuge and analyzed by a Jasco V-570 UV-visible spectrometer at $663 \mathrm{~nm}$.

For the catalytic degradation process, the same quantity of a catalyst was used for every batch test. PMS at $0.05 \mathrm{~g}$ was charged into MB solution to start the catalytic oxidation process. After certain time intervals, $1 \mathrm{~mL}$ of solution was withdrawn by a syringe and filtered by $0.45 \mu \mathrm{m}$ Millpore film and 0.5 $\mathrm{mL}$ methanol was injected into the filtered solution as a quenching reagent. The obtained mixtures were analyzed by the Jasco V-570 UV-vis spectrometer. In addition, $\mathrm{H}_{2} \mathrm{O}_{2}$ was also used as an oxidant for MB oxidation with A-RGO. A similar process as above was carried out with addition of $0.5 \mathrm{~mL}(30$ $\mathrm{wt} \%) \mathrm{H}_{2} \mathrm{O}_{2}$.

\section{Results and Discussion}

\subsection{Characterization of activated RGO samples}

Before the activation process, GO were first pretreated at $250{ }^{\circ} \mathrm{C}$ in $\mathrm{N}_{2}$ atmosphere. This pretreatment process can remove the oxygen containing groups (Fig. 2) and reduce the GO to RGO preliminarily ${ }^{12}$. The activation process with $\mathrm{CO}_{2}$ at $800{ }^{\circ} \mathrm{C}$ was then performed, and the production yields of activated RGO $\left(\mathrm{m}_{\mathrm{t}} / \mathrm{m}_{0}\right)$ at different activation periods are shown in Fig. 1a. The yield decreased greatly with a longer activation time, which is due to oxidation reaction between RGO and carbon dioxide at high temperature ${ }^{13}$. This reaction can slit RGO sheets and produce porous surface of RGO to increase the $\mathrm{SSA}^{7}$. The obtained samples were then characterized by nitrogen adsorption at $-196{ }^{\circ} \mathrm{C}$ to probe porous structure and the adsorption isotherms are shown in Fig. 1b. No porous structure could be observed for RGO (Fig. 1c, line 1). After short-time activation, the porous structure started to develop, and the majority of pores are narrowly distributed at $2.3 \mathrm{~nm}$ (Fig. 1c, line 2). Higher amounts of larger micropores and some mesopores were produced at longer activation periods (Fig. 1c, line 3). This porous structure can significantly increase the SSA of RGO. The SSA values at varying activation time are shown in Fig. 1d. It was found that the SSA of RGO increased significantly after 
activation and reached the maximum at the activation time of 60 min. Longer activation period, however, reduced SSA, which can be explained by the results of pore structure variation (Fig. 1c). A large amount of mesopores with pore size larger than $5 \mathrm{~nm}$ were produced on A-RGO-60, which resulted in increased SSA. While these pores (diameter $\geq 5 \mathrm{~nm}$ ) completely disappeared when the activation time was increased to $75 \mathrm{~min}$ (Fig. 1c, line 4). These larger mesopores have been transformed into macropores which cannot be detected by $\mathrm{N}_{2}$-adsorption, making A-RGO-75 presenting decreased $\mathrm{SSA}^{7,14}$. Therefore, $60 \mathrm{~min}$ is the optimized activation time to obtain porous RGO with the highest SSA.

\section{Figure 1}

Fourier transform infrared spectroscopy (FT-IR) spectra of the activated RGO samples are shown in Fig. 2. Several characteristic peaks $\left(1719 \mathrm{~cm}^{-1}\right.$ and $1612 \mathrm{~cm}^{-1}$ for COO group; $1039 \mathrm{~cm}^{-1}$ for C-O group) could be observed from Fig. 2 a to confirm the successful preparation of GO. Nearly all of the functional groups disappeared during the thermal reduction process $\left(250{ }^{\circ} \mathrm{C}\right)$ in $\mathrm{N}_{2}$ atmosphere (Fig $\left.2 \mathrm{~b}\right)$. The subsequent activation by $\mathrm{CO}_{2}$ will partially split and oxidize the RGO sheets at the same time, and generate some new functional groups $\left(\sim 1550 \mathrm{~cm}^{-1}\right.$ for $\mathrm{C}=\mathrm{O}$ and $\sim 1100 \mathrm{~cm}^{-1}$ for $\left.\mathrm{C}-\mathrm{O}\right)$ on the edges and surface of the RGO.

\section{Figure 2}

The formation of porous structure will result in an increase in the SSA of RGO, and this has been proven by $\mathrm{N}_{2}$ adsorption (Fig. 1). On the other hand, the activation will change the stability of graphene at the same time, and this conclusion can be supported by thermogravimetric analysis (TGA, Fig. 3). The TGA curves were obtained in air atmosphere at a heating rate of $10{ }^{\circ} \mathrm{C} / \mathrm{min}$. The combustion temperature was found to be in an order: $\mathrm{RGO}<\mathrm{A}-\mathrm{RGO}-75<\mathrm{A}-\mathrm{RGO}-60<\mathrm{A}-\mathrm{RGO}-25$. As shown in Fig. 
3a for RGO, a slight weight loss occurred until the temperature was raised to $440{ }^{\circ} \mathrm{C}$. Then the carbon skeletons of RGO started to be broken down due to combustion in air, which shows a characteristic weight loss between $440 \sim 600{ }^{\circ} \mathrm{C}$. As for the samples after activation, the combustion temperature was increased by $80 \sim 100{ }^{\circ} \mathrm{C}$. In this investigation, $\mathrm{CO}_{2}$ activation occurred at $800{ }^{\circ} \mathrm{C}$. Before introduction of $\mathrm{CO}_{2}$, thermal treatment in $\mathrm{N}_{2}$ could further reduce $\mathrm{GO}$ by removing oxygen functional groups. It has been proved that the $\mathrm{C} / \mathrm{O}$ ratio was no more than 7 when the treatment temperature is $\sim 250{ }^{\circ} \mathrm{C}$. While the $\mathrm{C} / \mathrm{O}$ ratio could be higher than 13 if the temperature reached $\sim 800{ }^{\circ} \mathrm{C}^{12,15}$. Therefore, the delay in combustion on A-RGOs could be attributed to the removal of residual oxygen containing groups during continuing thermal reduction process of GO at high temperature, making the activated RGO more thermally stable in air atmosphere. Meanwhile, the activation process by $\mathrm{CO}_{2}$ can produce active edge defects and functional groups on the RGO. The burn-off temperature became lower at increased activation time.

Another important evidence to show the activation process is Raman spectra (Fig. 4). All Raman spectra of the obtained materials (Fig. 4a-d) show strong D bands centered at $1320 \mathrm{~cm}^{-1}$, implying the presence of a large amount of defects. The $\mathrm{I}_{\mathrm{D}} / \mathrm{I}_{\mathrm{G}}$ follows this order: RGO (2.717) $<\mathrm{A}-\mathrm{RGO}-25$ $(2.864)<\mathrm{A}-\mathrm{RGO}-60(2.934)<\mathrm{A}-\mathrm{RGO}-75$ (3.162). The intensity ratio of $\mathrm{D}$ - and G-peaks $\left(\mathrm{I}_{\mathrm{D}} / \mathrm{I}_{\mathrm{G}}\right)$ will be increased with decay of size of the perfect graphene units. The above order indicates that activation process will break up the typical $\mathrm{sp}^{2}$ structure and produce new active edges and functional groups. Longer activation time will produce more decay on the surface of RGO.

\section{Figure 3}

\section{Figure 4}

\subsection{Adsorption of Phenol}

The obtained RGO samples were tested for phenol adsorptive removal from aqueous solutions, and the Freundlich model was employed to analyze the adsorption isotherms (Fig.5). This model assumes 
that adsorption occurs on a heterogeneous surface through a multilayer adsorption mechanism, and that the adsorbed amount increases with the concentration according to the following equation: $\mathrm{q}_{\mathrm{e}}=\mathrm{K}_{\mathrm{F}} \mathrm{C}_{\mathrm{e}}{ }^{1 / \mathrm{n}}$, where $\mathrm{q}_{\mathrm{e}}$ and $\mathrm{C}_{\mathrm{e}}$ are the equilibrium concentrations of the adsorbate in sorbent and solution, respectively. $\mathrm{K}_{\mathrm{F}}$ is the Freundlich constant related to the adsorption capacity $\left(\mathrm{mg} / \mathrm{g} \cdot(\mathrm{mg} / \mathrm{L})^{\mathrm{n}}\right)$, equal to the amount adsorbed at the value of $\mathrm{C}_{\mathrm{e}}$ equal to unity and $\mathrm{n}$ is the empirical parameter representing the energetic heterogeneity of the adsorption sites (dimensionless). $\mathrm{R}^{2}$ is the value of coefficient of determination ${ }^{1}$. The Freundlich parameters are shown in Table 1. It can be found from the adsorption results that the $\mathrm{K}_{\mathrm{F}}$ follows the order: RGO (0.688) < A-RGO-25 (3.79) <A-RGO-75 (5.321) < A-RGO60 (6.403). This order is conformed well to the SSA results. In addition, the $\mathrm{R}^{2}$ values are very close to 1, indicating that the adsorption isotherms are very well modeled by the Freundlich equation. Compared to activated carbon $\left(\mathrm{C}_{\mathrm{e}}=50 \mathrm{mg} / \mathrm{L}, \mathrm{q}_{\mathrm{e}} \sim 130 \mathrm{mg} / \mathrm{g}\right)$ and $\mathrm{CNT}\left(\mathrm{C}_{\mathrm{e}}=50 \mathrm{mg} / \mathrm{L}, \mathrm{q}_{\mathrm{e}} \sim 20 \mathrm{mg} / \mathrm{g}\right)$, the activated graphene (A-RGO-60) has a much better capacity $\left(\mathrm{C}_{\mathrm{e}}=50 \mathrm{mg} / \mathrm{L}, \mathrm{q}_{\mathrm{e}} \sim 200 \mathrm{mg} / \mathrm{g}\right)$ towards phenol adsorption in the tested concentration range ${ }^{16,17}$.

\section{Table 1}

\section{Figure 5}

\subsection{MB adsorption and catalytic oxidation}

Before the catalytic oxidation, the dynamic adsorption behavior of RGO and A-RGO samples for MB was first investigated. As shown in Fig. 6a, MB adsorption on the obtained materials is a fast process, and equilibriums could be reached in about $90 \mathrm{~min}$ for all the materials. The adsorption ability follows the same order as in phenol adsorption: RGO $<$ A-RGO-25 $<$ A-RGO-75 $<$ A-RGO-60. This order is also conformed well to the SSA results. For the RGO, only less than $30 \% \mathrm{MB}$ removal can be obtained, and the removal efficiency was increased to higher than $65 \%$ on the A-RGO- 60 . 
Fig. $6 \mathrm{~b}$ shows the oxidative MB degradation efficiency with the addition of PMS catalyzed by the obtained materials. PMS was able to degrade $\sim 80 \%$ MB in 4 h by self-oxidation without the presence of a catalyst. With the addition of carbon catalysts, MB removal process becomes much faster. The overall removal efficiency of MB follows an order: A-RGO-60 >A-RGO-25 >A-RGO-75 > RGO. For RGO, $100 \% \mathrm{MB}$ removal would be achieved in $4 \mathrm{~h}$, and this time can be reduced to $1.5 \mathrm{~h}$ on A-RGO25, $1.0 \mathrm{~h}$ on A-RGO-60, and $2 \mathrm{~h}$ on A-RGO-75.

It was reported in our previous study that structure defective graphene was able to effectively activate PMS to produce active sulfate radicals ${ }^{10}$. The oxygen functional surface species, such as ketonic $(\mathrm{C}=\mathrm{O})$ groups, are rich in electrons and thus have a great potential to coordinate a redox process. The mechanism for PMS activation and MB oxidation are shown in Eqs.(1-4). The catalytic activities of the materials depend on the presence of oxygen containing groups. The RGO was obtained at a relatively low temperature $\left(250^{\circ} \mathrm{C}\right)$ with little functional groups (Fig.2). After 25 min treatment in $\mathrm{CO}_{2}$ at $800{ }^{\circ} \mathrm{C}$, some functional groups would be generated by $\mathrm{CO}_{2}$. At increased activation period, more oxygen containing groups would be produced (Fig. 2). A-RGO-60 has the higher level of functional groups and catalytic activity in PMS activation. Meanwhile, heterogeneous oxidation of MB will be involved $\mathrm{MB}$ adsorption process and higher SSA will promote $\mathrm{MB}$ adsorption on carbon surface. Taking both the adsorption and catalytic ability together, A-RGO-60 was the best material for MB removal from aqueous solution.

$$
\begin{aligned}
& \mathrm{HSO}_{5}{ }^{-}+\mathrm{C}=\mathrm{C}-\mathrm{O} \rightarrow \mathrm{SO}_{4}{ }^{-}+\mathrm{C}=\mathrm{C}^{-} \mathrm{O}^{+}+\mathrm{HO}^{-} \\
& \mathrm{HSO}_{5}{ }^{-}+\mathrm{C}=\mathrm{C}^{-} \mathrm{O}^{+} \rightarrow \mathrm{SO}_{5}{ }^{-}{ }^{-}+\mathrm{C}=\mathrm{C}-\mathrm{O}+\mathrm{H}^{+} \\
& \mathrm{SO}_{4}{ }^{-}{ }^{-}+\mathrm{MB}^{+} \rightarrow \mathrm{SO}_{4}{ }^{-} \cdot \mathrm{MB}^{+} \rightarrow \text { several steps } \rightarrow \mathrm{SO}_{4}{ }^{2-}+\mathrm{CO}_{2}+\mathrm{H}_{2} \mathrm{O} \\
& \mathrm{SO}_{5}{ }^{-}{ }^{-}+\mathrm{MB}^{+} \rightarrow \mathrm{SO}_{5}{ }^{-}{ }^{-} \cdot \mathrm{MB}^{+} \rightarrow \text { several steps } \rightarrow \mathrm{SO}_{4}{ }^{2-}+\mathrm{CO}_{2}+\mathrm{H}_{2} \mathrm{O}
\end{aligned}
$$

Another oxidant, $\mathrm{H}_{2} \mathrm{O}_{2}$, is widely used for hydroxyl radical generation and organic oxidation. In this investigation, $\mathrm{H}_{2} \mathrm{O}_{2}$ was also tested for MB catalytic oxidation using A-RGO-75 as the catalyst, and the 
result is shown in Fig. 6c. The A-RGO-75 was selected for the tests due to its moderate adsorption capacity and characteristics of activated graphene structure. It is seen that overall MB degradation efficiency at the presence of $\mathrm{H}_{2} \mathrm{O}_{2}$ is higher than that of adsorption, suggesting that A-RGO-75 also exhibited activity in $\mathrm{H}_{2} \mathrm{O}_{2}$ activation. Compared with PMS activation, A-RGO-75 presented much lower activity in $\mathrm{H}_{2} \mathrm{O}_{2}$ activation to generate hydroxyl radicals. In terms of $\mathrm{MB}$ degradation, only $50 \%$ MB was removed when $\mathrm{H}_{2} \mathrm{O}_{2}$ was used. Moreover, no further $\mathrm{MB}$ could be removed at extended period to $4.5 \mathrm{~h}$. Some investigations on $\mathrm{H}_{2} \mathrm{O}_{2}$ activation by activated carbon have shown that activated carbon presented low activity in activation of $\mathrm{H}_{2} \mathrm{O}_{2}$ to produce hydroxyl radicals ${ }^{18,19}$.

\section{Conclusions}

$\mathrm{CO}_{2}$ activation process was successfully employed to produce porous reduced graphene oxide (ARGO) from chemically synthesized GO using a facile one-pot thermal method. Activation time influences porous structure, chemical functionality, adsorption capacity and catalytic activity of ARGO. The resulted materials show much higher SSA and are very efficient for the adsorptive removal of phenol and MB from aqueous solutions. The RGO and A-RGO materials were also found to be effective in metal free activation of PMS for oxidation of MB. These A-RGO materials can be green materials for environmental-benign processes in adsorption and catalysis.

\section{Acknowledgement}

This project is partially supported by the Australian Research Council under project No: DP130101319.

\section{References}

1. S. J. Zhang, T. Shao, H. S. Kose and T. Karanfil, Environ Toxicol Chem, 2012, 31, 79-85. 
2. L. M. Zhang, S. O. Diao, Y. F. Nie, K. Yan, N. Liu, B. Y. Dai, Q. Xie, A. Reina, J. Kong and Z. F. Liu, J. Am. Chem. Soc., 2011, 133, 2706-2713.

3. J. G. Hou, Z. Wang, W. B. Kan, S. Q. Jiao, H. M. Zhu and R. V. Kumar, J Mater Chem, 2012, 22, 7291-7299.

4. Y. W. Zhu, S. Murali, W. W. Cai, X. S. Li, J. W. Suk, J. R. Potts and R. S. Ruoff, Adv Mater, 2010, 22, 3906-3924.

5. P. Bradder, S. K. Ling, S. Wang and S. Liu, J. Chem. Eng. Data, 2011, 56, 138-141.

6. B. Tryba, A. W. Morawski and M. Inagaki, Carbon, 2005, 43, 2417-2419.

7. T. G. Xu, L. W. Zhang, H. Y. Cheng and Y. F. Zhu, Appl. Catal. B, 2011, 101, 382-387.

8. S. Murali, J. R. Potts, S. Stoller, J. Park, M. D. Stoner, L. L. Zhang, Y. W. Zhu and R. S. Ruoff, Carbon, 2012, 50, 3482-3485.

9. P. R. Shukla, S. Wang, H. Sun, H. M. Ang and M. Tade, Appl. Catal. B, 2010, 100, 529-534.

10. H. Q. Sun, S. Z. Liu, G. L. Zhou, H. M. Ang, M. O. Tade and S. B. Wang, ACS Appl Mater Inter, 2012, 4, 5466-5471.

11. W. S. Hummers Jr and R. E. Offeman, J Am Chem Soc, 1958, 80, 1339-1339.

12. C. D. Zangmeister, Chem Mater, 2010, 22, 5625-5629.

13. M. Turmuzi, W. R. W. Daud, S. M. Tasirin, M. S. Takriff and S. E. Iyuke, Carbon, 2004, 42, 453-455.

14. K. S. Xia, Q. M. Gao, S. Q. Song, C. D. Wu, J. H. Jiang, J. Hu and L. Gao, Int J Hydrogen Energ, 2008, 33, 116-123.

15. H. C. Schniepp, J. L. Li, M. J. McAllister, H. Sai, M. Herrera-Alonso, D. H. Adamson, R. K. Prud'homme, R. Car, D. A. Saville and I. A. Aksay, J Phys Chem B, 2006, 110, 8535-8539.

16. V. Fierro, V. Torne-Fernandez, D. Montane and A. Celzard, Micropor Mesopor Mat, 2008, 111, $276-284$. 
17. A. H. Norzilah, A. Fakhru'l-Razi, T. S. Y. Choong and A. L. Chuah, J Nanomater, 2011, Artn 495676.

18. H. T. Gomes, S. M. Miranda, M. J. Sampaio, J. L. Figueiredo, A. M. T. Silva and J. L. Faria, Appl. Catal. B, 2011, 106, 390-397.

19. A. Rey, J. A. Zazo, J. A. Casas, A. Bahamonde and J. J. Rodriguez, Appl. Catal. A, 2011, 402, $146-155$. 


\section{Tables}

Table 1: The coefficients of the Freundlich isotherms for phenol adsorption.

\begin{tabular}{ccccc}
\hline Materials & $\mathrm{K}_{\mathrm{F}}\left(\mathrm{mg} / \mathrm{g} \cdot(\mathrm{mg} / \mathrm{L})^{\mathrm{n}}\right)$ & $1 / \mathrm{n}$ & $\mathrm{n}$ & $\mathrm{R}^{2}$ \\
\hline RGO & 0.688 & 1.246 & 0.802 & 0.967 \\
A-RGO-25 & 3.79 & 0.979 & 1.021 & 0.975 \\
A-RGO-60 & 6.403 & 0.915 & 1.093 & 0.994 \\
A-RGO-75 & 5.321 & 0.906 & 1.103 & 0.993 \\
\hline
\end{tabular}




\section{Figure Captions}

Fig. 1. (a) Effects of $\mathrm{CO}_{2}$ activation time upon yield; (b) Nitrogen adsorption isotherms of RGO and activated RGOs at $77 \mathrm{~K}$; (c) Pore size distribution of RGO and activated RGOs; (d) Effects of $\mathrm{CO}_{2}$ activation time upon SSA.

Fig. 2. FT-IR of GO (a), RGO (b), A-RGO-25 (c), A-RGO-60 (d), and A-RGO-75 (e)

Fig. 3. TGA curves of RGO (a), A-RGO-25 (b), A-RGO-60 (c), and A-RGO-75 (d) in air atmosphere.

Fig. 4 Raman spectra of RGO (a 0.30), A-GRO-25 (b 0.35), A-RGO-60 (c 0.34), and A-RGO-75 (d $0.32)$.

Fig. 5. Phenol adsorption isotherms of RGO and activated RGO materials at $25{ }^{\circ} \mathrm{C}$

Fig. 6 (a) MB adsorption removal by RGO based materials; (b) MB removal with PMS as oxidant and A-RGO materials as adsorbents and catalysts; (c) MB removal with different oxidants catalyzed by ARGO-75 


\section{List of Figures}
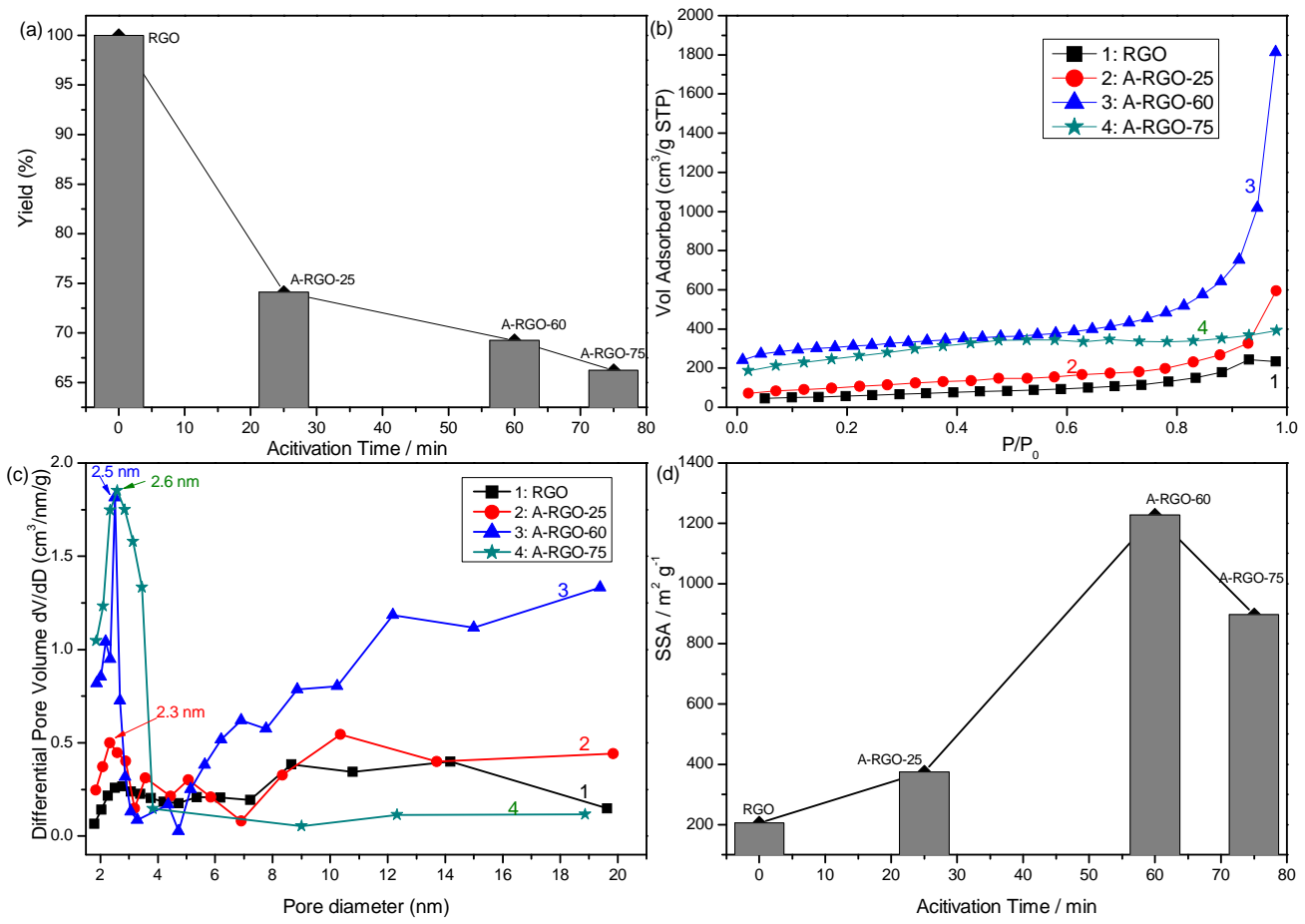

Fig. 1. 


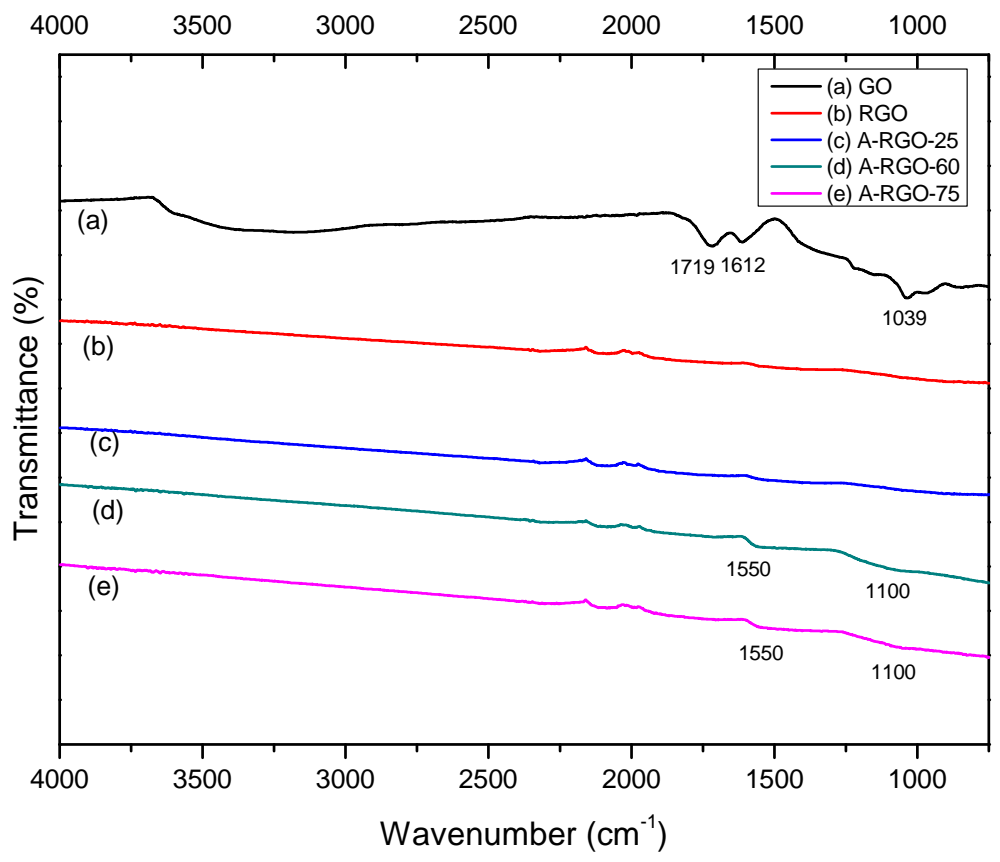

Fig. 2. 


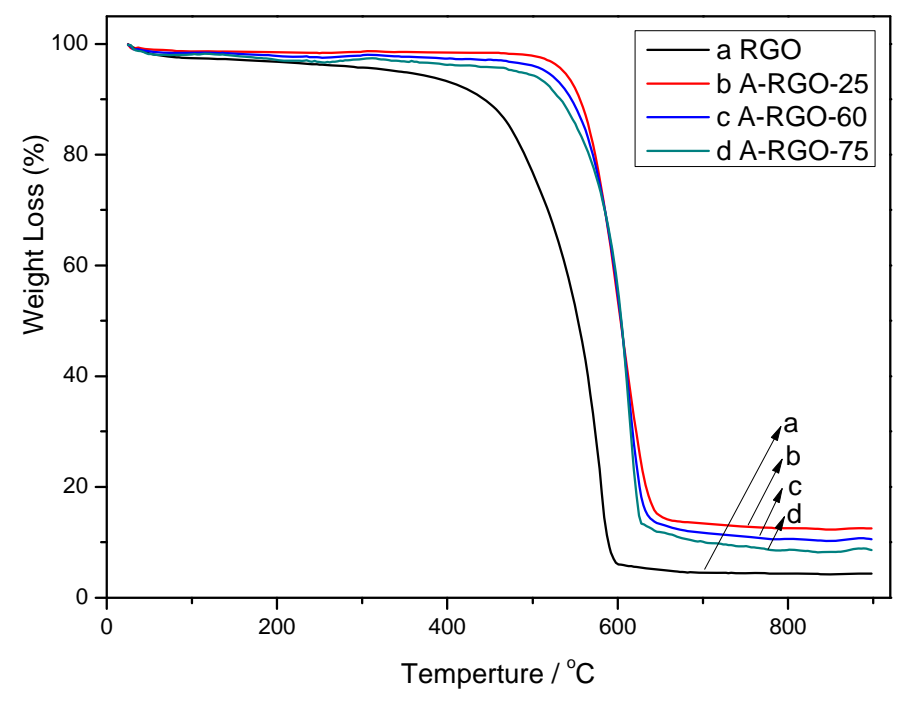

Fig. 3. 


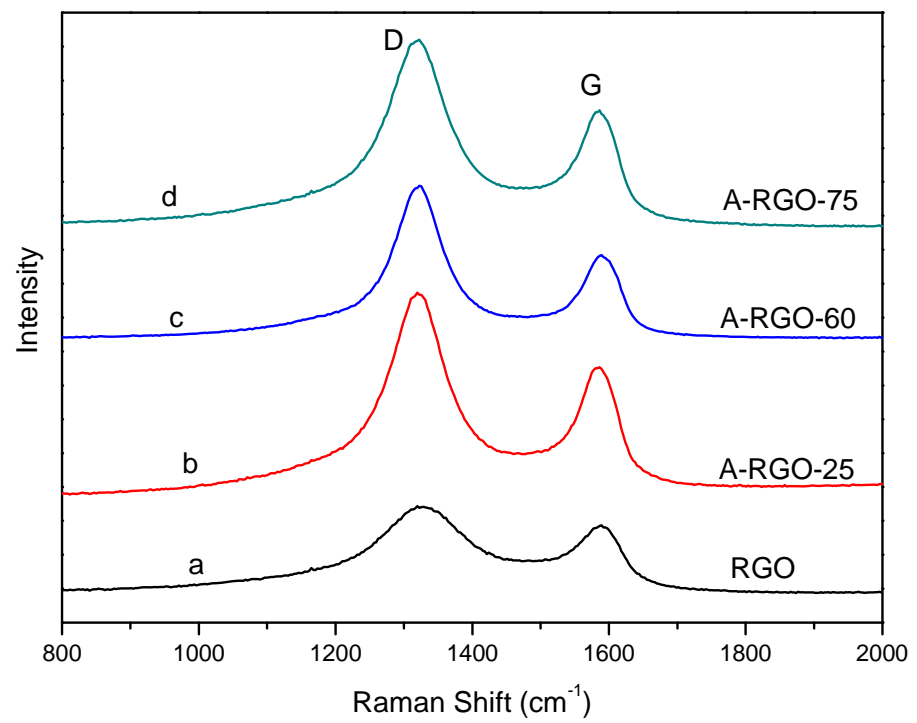

Fig. 4. 


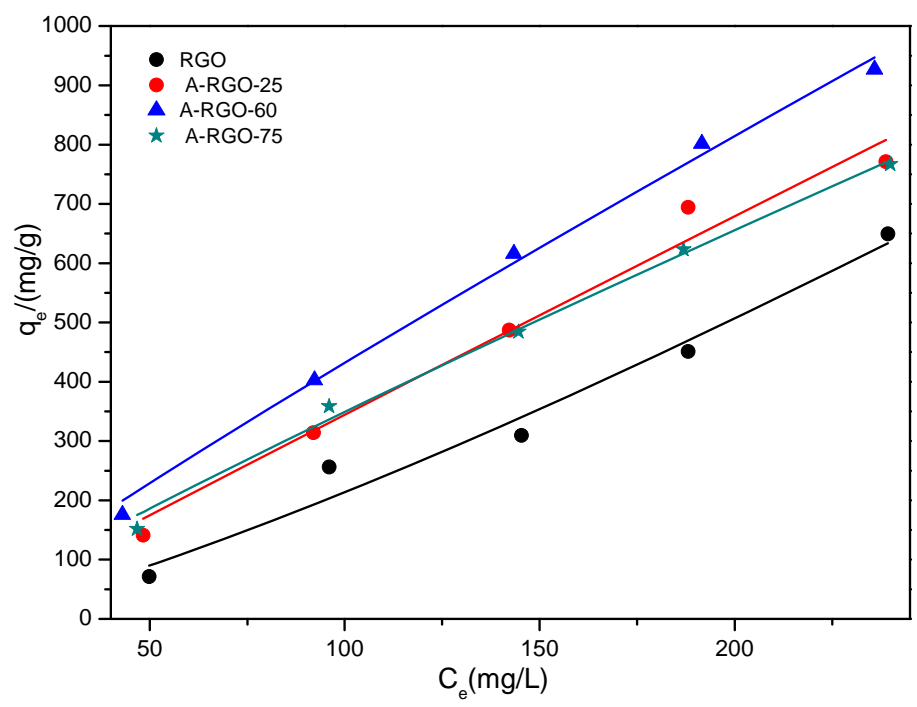

Fig. 5. 


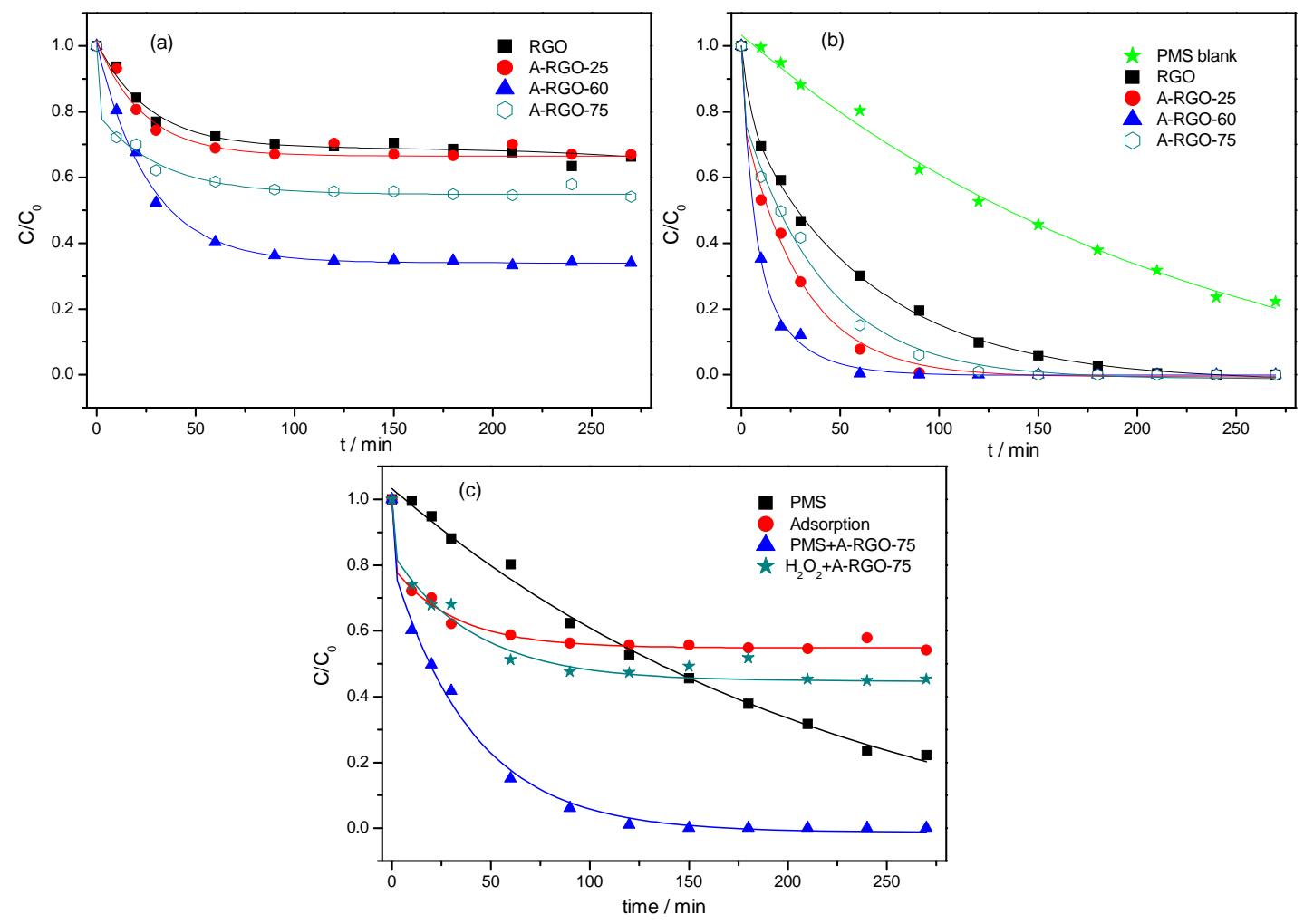

Fig. 6 